\title{
Overview of Ductal Carcinoma in Situ of the Breast
}

\section{Papa Macoumba Gaye*, Abdoul Aziz Kassé}

Institut du Cancer de Dakar, Dakar, Senegal.

Email: *pmgaye@hotmail.com

Received November $9^{\text {th }}, 2013$; revised December $9^{\text {th }}$, 2013; accepted December $17^{\text {th }}, 2013$

Copyright (c) 2014 Papa Macoumba Gaye, Abdoul Aziz Kassé. This is an open access article distributed under the Creative Commons Attribution License, which permits unrestricted use, distribution, and reproduction in any medium, provided the original work is properly cited. In accordance of the Creative Commons Attribution License all Copyrights (c) 2014 are reserved for SCIRP and the owner of the intellectual property Papa Macoumba Gaye, Abdoul Aziz Kassé. All Copyright (C 2014 are guarded by law and by SCIRP as a guardian.

\section{ABSTRACT}

We review relevant publications on ductal carcinoma in situ of the breast in the past three years and we discuss pattern of outcome lightened by new molecular approach and techniques of radiotherapy.

\section{KEYWORDS}

\section{DCIS; Radiotherapy; Treatment}

\section{Introduction}

Ductal carcinoma in situ (DCIS) of breast is defined by the presence of cancer cells inside a milk duct in the breast. DCIS is considered as infra clinic preinvasive form of breast cancer. DCIS is not rare, accounting for about $20 \%$ of breast cancer cases. Progress in tumor biology is helping to identify the factors of recurrence after surgery. However radiotherapy remains a cornerstone of the treatment. Randomized trials are aiming to select the best adjuvant treatment. The purpose is also to move from radical agressive therapy to adaptative treatment including discussion on type of surgery, volume to be irradiated, dose and fractionnation of radiotherapy, boost or no boost.

\section{Diagnosis}

DCIS is usually revealed by mammogram in a breast cancer screening process. Because of development of cancer control programs, diagnosis of DCIS has increased in this past decade. Calcifications are not present in all cases and lesions can be occult mammographically, contributing to a sensitivity of $70 \%-80 \%$ [1].

As the extent of disease is underestimated, breast MRI has emerged as a main tool for diagnosis and characterization of DCIS with a sensitivity of $77 \%$ to $96 \%$ [2]. The presentation as a mass is rare but possible [3].

"Corresponding author.

\section{Surgery and Radiotherapy}

The van Nyus criteria is the most common system used to predict recurrence after treatment. This classification has identified 3 groups taking into account size of tumor, margin after surgery and pathological grade. This system has been confirmed as a good prognosis factor by a recent cohort study of 4578 patients diagnosed with DCIS enrolled by Whitfield and al. [4].

In a recent review of seventeen DCIS randomized trials, a stratification in high, intermediate or low risk was achieved, including different parameters: age, positive estrogen receptors $(\mathrm{ER}+)$, use of tamoxifen and extent of surgery.

Conventional radiotherapy (50 Gy in 25 fractions) has reduced the 15-year cancer death in the high, low and intermediate risk groups in respectively $7.8 \%, 1.1 \%$, and $0.1 \%$.

The local recurrence decreased of $60 \%$ with this adjuvant irradiation without impact on metastases or survival.

Size, pathological subtype and margins were the major risk factors for local recurrence after breast conserving therapy. [5].

Results of NSABP trial have confirmed hypofractionnated regimens of radiotherapy as an option. In this approach, different techniques can be been used: - 3D conformal radiotherapy with 15 fractions of 2.8 Gy for non palpable initial tumor, with negative or close marginsafter surgery and no residual microcalcification-IMRT 
with 15 fractions of 2.7 Gy to the breast plus 0.5 Gy daily integrated boost to surgical cavity.[6]

The independent effect of boost radiation on the development of local recurrence has been evaluated. All women diagnosed with DCIS and treated with breastconserving surgery and radiation therapy in Ontario from 1994 to 2003 were identified. Treatments and outcomes were noted through administrative databases and validated by chart review. The impact of boost radiation on the development of local recurrence was determined using survival analysis.

In this population cohort the administration of boost radiation does not decrease the risk of recurrence [7].

Skin-sparing mastectomy is an option in the treatment of DCIS without micro invasion. A retrospective study is reported on one hundred and forty-five consecutive women treated from 1998 to 2005 for pure DCIS bymastetomy with or without radiation. Patients with microinvasion were excluded. The primary endpoint was local recurrence, defined as recurrence on the chest wall. Regional and distant recurrences were secondary endpoints.

Outcomes were analyzed according to margin status [positive, close (2 mm), or negative], location of the closest margin in the breast (superficial, deep, or both), nuclear grade, necrosis, receptor status, type of mastectomy, and hormonal therapy.

In this study, patients treated with skin-sparing mastectomy with unfavorable features such as high-grade disease also seemed to have a very low risk of chest wall recurrence and there is no benefit for radiotherapy.

We are strongly moving to a new molecular approach of biopsy samples looking forward DCIS. In a recent publication, basal cytokeratin seems to be a potential marker in ductal carcinoma in situ: the immunoexpression of basal CK 5/6 in both high-grade and low-grade DCIS lesions indicates a lower risk of invasive carcinoma [8].

Presence of microinvasion (DCISM) is an issue in this pathologic analysis, even if its prognostic implication is unclear.

Rahul and al reported results of 393 patients with DCIS/DCISM from a database analyzed to assess differrences in clinical-pathologic features and outcomes of 2 cohorts, to examine the rate of local recurrence. The natural history of DCISM closely resembles that of DCIS, with a low incidence of local-regional and distant failuresafter treatment [9].

\section{Adjuvant Hormonotherapy}

Discussion of adjuvant treatment is sustained by the specific aim of decreasing risk of invasive disease after surgery and radiotherapy. The NSABP performed a double-blind prospective trial (NSABP-B-24) to mesure efficiency of tamoxifen for 1804 women with $20 \%$ clinical disease and $23 \%$ of positive or unknown margins. Patients were randomly assigned to conservative treatment (lumpectomy plus 50 Gy radiotherapy), with versus no tamoxifen (20 mg/day for five years). Breast cancer events were defined as the presence of new ipsilateral disease, contralateral disease, or metastases. Women in the tamoxifen group had fewer breast cancer events at five years ( $8.2 \%$ vs. $13.4 \% ; P=0.009)$ [10].

With tamoxifen, ipsilateral invasive breast cancer decreased from $4.2 \%$ to $2.1 \%$ at 5 years $(P=0.03)$. The incidence of contralateral breast neoplasms (invasive and noninvasive) also decreased from $0.8 \%$ per year to $0.4 \%$ per year $(P=0.01)$. The benefit of tamoxifen extended to those patients with positive or uncertain margins.

But the risk of invasive breast cancer or recurrent DCIS in the remaining breast tissue is very small [11].

\section{Conclusion}

The prognosis of DCIS remains good after conservative surgery and radiotherapy or mastectomy alone. Parallel to Van nyus factors novel molecular markers could be useful for selecting group who will benefit of adjuvant stereotactic radiotherapy.

\section{REFERENCES}

[1] V. L. Ernster, R. Ballard-Barbash, W. E. Barlow, et al., "Detection of Ductal Carcinoma in Situ in Women Undergoing Screening Mammography," Journal of the National Cancer Institute, Vol. 94, No. 20, 2002, pp. 15461554. http://dx.doi.org/10.1093/jnci/94.20.1546

[2] E. Morris and L. Liberman, "Ductal Carcinoma in Situ," In: E. A. Morris and L. Liberman, Eds., Breast MRI: Diagnosis and Intervention, Springer, Philadelphia, 2004.

[3] J. Richard. L. A. Lee, S. A. Vallow, McLaughlin, K. S. Tzou, S. L. Hines and J. L. Peterson. "Ductal Carcinoma in Situ of the Breast," International Journal of Surgical Oncology, Vol. 2012, 2012, Article ID 123549. http://dx.doi.org/10.1155/2012/123549

[4] R. Whitfield, J. Kollias, P. de Silva, J. Turner and G. Maddern, "Management of Ductal Carcinoma in Situ according to Van Nuys Prognostic Index in Australia and New Zealand,” ANZ Journal of Surgery, Vol. 82, No. 7-8, 2012, pp. 518-523. http://dx.doi.org/10.1111/j.1445-2197.2012.06133.x

[5] S. F. Shaitelman, J. B. Wilkinson, L. L. Kestin, H. Ye, N. S. Goldstein, A. A. Martinez and F, A. Vicini, "Long Term Outcome in Patients with ductal Carcinoma in Situ Treated with Breast Conserving Therapy: Implications for Optimal Follow up Strategies," International Journal of Radiation Oncology * Biology * Physics, Vol 83, No. 3, 2012, pp. 305-312.

[6] S. K. Childs, Y.-H. Chen, M. M. Duggan, M. Golshan, S. Pochebit, R. S. Punglia, J. S. Wong and J. R. Bellon. "Impact of Margin Status on Local Recurrence after Mastectomy for Ductal Carcinoma in Situ," International Journal of Radiation Oncology * Biology * Physics, Vol. 
85, No. 4, 2013, pp. E948-E952.

[7] E. Rakovitch, S. A. Narod, S. Nofech-Moses, W. Hanna, D. Thiruchelvam, R. Saskin, C. Taylor, A. Tuck, B. Yougson, N, Miller, S. J. done, S. Sengupta, L. Elavathil, P. A. Jani, M. Bonin, S. Metcalfe and L. Paszat, "Impact of Boost Radiation in the Treatment of Ductal Carcinoma in Situ: A Population-Based Analysis,” International Journal of Radiation Oncology * Biology * Physics, Vol. 86, No. 3, 2013, pp. 491-497. http://dx.doi.org/10.1016/j.ijrobp.2013.02.031

[8] F. N. Aguiar, H. N. Mendes, C. S. Cirqueira, C. E. Bacchi and F. M. Carvalho, "Basal cytokeratin as a potential marker of low risk of invasion in ductal carcinoma in situ," Clinics (Sao Paulo), Vol. 68, No. 5, 2013, pp. 638-64. http://dx.doi.org/10.6061/clinics/2013(05)010

[9] R. R. Parikh, B. G. Haffty, D. Lannin and M. S. Moran, "Ductal Carcinoma in Situ With Microinvasion: Prog- nostic Implications, Long-Term Outcomes, and Role of Axillary Evaluation,” International Journal of Radiation Oncology * Biology * Physics, Vol. 82, No. 1, 2012, pp. 7-13.

[10] B. Fisher, J. Dignam, N. Wolmark, et al., "Tamoxifen in Treatment of Intraductal Breast Cancer: National Surgical Adjuvant Breast and Bowel Project B-24 Randomised Controlled Trial,” Lancet, Vol. 353, No. 9169, 1999, pp. 1993-2000.

http://dx.doi.org/10.1016/S0140-6736(99)05036-9

[11] J. Houghton, W. D. George, J. Cuzick, et al., "Radiotherapy and Tamoxifen in Women with Completely Excised Ductal Carcinoma in Situ of the Breast in the UK, Australia, and New Zealand: Randomised Controlled Trial," Lancet, Vol. 362, No. 9378, 2003, pp. 95-102. http://dx.doi.org/10.1016/S0140-6736(03)13859-7 